\title{
EARLY CHILDHOOD CARIES (ECC) PADA ANAK USIA PRASEKOLAH DI DUSUN WANASARI KECAMATAN DENPASAR UTARA
}

\author{
Eko Sri Yuni Astuti, Fitri Rochmawati \\ Bagian Ilmu Kedokteran Gigi Anak, Fakultas Kedokteran Gigi, Universitas Mahasaraswati Denpasar \\ Email : pedo_yuni@yahoo.co.id
}

\begin{abstract}
Early Childhood Caries (ECC) is caries that destroyed maxillary insicives desidui after they erupt few month with specific pattern on children under 71 month of age. Prevalence of ECC in developed countries are low, but still high in developing countries, especially Indonesia. Dusun Wanasari is a village in subdistrict of South Denpasar of Bali that evarage of people with low income. Most of the parents in Dusun Wanasari are good in assisting their children on oral health maintenance. The aim of this research was to know the prevalence of ECC on preschool children in Dusun Wanasari. These research used diskriptive method and Survey was taken with quesioner which collaborate data of ECC. Thirty preschool children 3-5 years of age, as responden. Result showed that $80 \%$ children have ECC and 20\% were free of ECC. It's mean the prevalence of ECC on preschool children in Dusun Wanasari was still high. Improper feeding pattern, such us bottle feeding and consumed cariogenic food. Poor oral hygiene and low awareness and behavior of oral health in low educated parents, were factor in occurring ECC.
\end{abstract}

Keywords : preschool children, early childhood caries, prevalence.

\section{PENDAHULUAN}

Sampai saat ini karies masih menjadi masalah kesehatan gigi dan mulut di Indonesia, karies bisa mengenai anak-anak ataupun orang dewasa. Early Childhood Caries (ECC) adalah salah satu bentuk karies yang merusak gigi insisivus sulung maxilla dalam beberapa bulan setelah erupsi dengan suatu pola lesi karies yang unik. Secara umum ECC merupakan suatu karies rampan yang di sebabkan oleh pemberian susu melalui botol atau ASI yang tidak benar. ${ }^{1}$ American Dental Association (ADA) mendefinisikan ECC sebagai adanya satu atau lebih kerusakan (lesi berkavitasi atau tidak berkavitasi), kehilangan (akibat karies) atau permukaan gigi yang ditambal pada gigi sulung anak yaitu dari sejak lahir hingga 71 bulan. ${ }^{2}$ Terjadinya karies pada anak usia $<3$ tahun menunjukkan suatu bentuk Severe Early Childhood Caries (S-ECC). Istilah S-ECC menunjukkan suatu pola karies gigi yang progresif, akut atau rampan. ${ }^{3}$

Proses terjadinya ECC sebenarnya sama saja dengan karies yaitu interaksi antara empat faktor yaitu, gigi (host), substrat (karbohidrat), mikroorganisme (bakteri), dan waktu, tetapi yang membedakannya dengan karies lain yaitu faktor penggunaan susu botol dalam jangka waktu yang panjang. ECC merupakan penyakit yang sering dialami bayi, balita dan anak prasekolah dan perkembangannya sangat cepat. ECC biasa terjadi beberapa bulan setelah gigi sulung erupsi. Beberapa gigi terkena karies, dimulai pada servikal gigi insisivus sulung maksila, diteruskan dengan kaninus. Jika penyakit ini terus berkembang, gigi molar pun turut terkena karies dengan hanya gigi insisivus mandibula yang bebas karies. ${ }^{4,5}$

Gambaran klinis ECC terdiri dari empat tahap yaitu: 1) Tahap satu/ insisal, terjadi pada anak usia antara 10-20 bulan atau lebih muda, karies diawali dengan garis berwarna putih seperti kapur, opak (white spots) pada insisivus maksila, gigi ini yang pertama erupsi pada rahang atas dan paling sedikit dilindungi oleh saliva. ${ }^{4,6}$

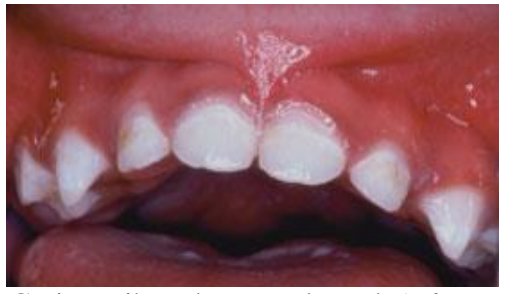

Gambar 1. Garis putih pada enamel, opak (white spot), tanda awal karies ${ }^{5}$

2) Tahap dua, kerusakan/karies terjadi ketika anak berusia 16-24 bulan. Lesi putih pada insisivus berkembang dengan cepat dan menyebabkan demineralisasi enamel sehingga mengenai dan terbukanya dentin.

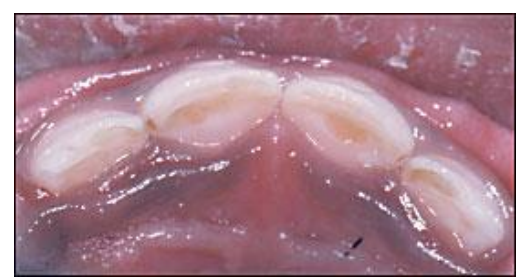

Gambar 2. Demineralisasi enamel dan terbukanya permukaan dentin, kavitas kuning-coklat pada permukaan lingual gigi ${ }^{5}$

3) Tahap tiga (lesi yang dalam), terjadi ketika anak berusia 20-36 bulan, lesi sudah meluas pada insisivus sulung maksila, hingga terjadi iritasi pulpa.

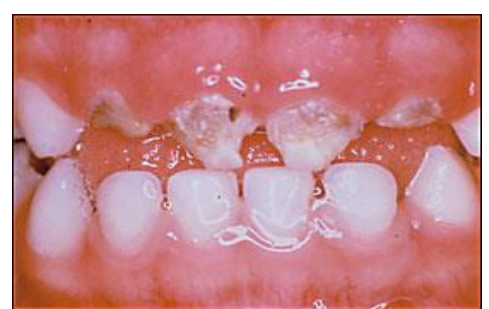

Gambar 3. Lesi sudah meluas pada insisivus sulung maksila, hingga terjadi iritasi pulpa ${ }^{5}$ 
4)Tahap empat (traumatik), terjadi ketika anak berusia antara 30-48 bulan, lesi meluas dengan cepat ke seluruh permukaan enamel dan dentin, mengelilingi permukaan servikal, dalam waktu singkat, terjadi kerusakan yang parah di seluruh mahkota gigi hingga terjadi fraktur dan hanya akar yang tersisa.

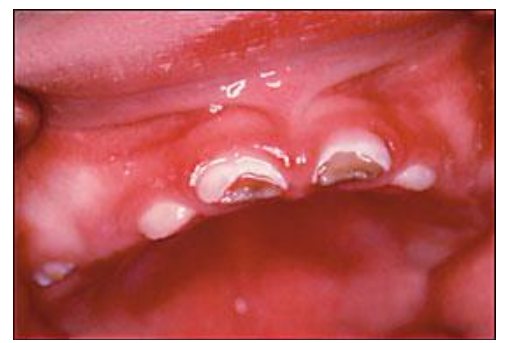

Gambar 4. Lesi meluas pada seluruh mahkota insisivus maksila $^{5}$

Center for Disease Control and Prevention menunjukkan bahwa penggunaan susu botol bukanlah penyebab ECC satu-satunya. ${ }^{7}$ Schroth tahun 2007 juga mendukung pernyataan tersebut dan menyebutkan bahwa ECC merupakan penyakit multifaktorial yang dipengaruhi oleh sosioekonomi, kebiasaan, psikososial, jumlah streptokokus mutan yang tinggi, diet yang tidak tepat, buruknya oral hygiene anak, dan lain-lain. ${ }^{8}$

Prevalensi karies pada anak-anak usia prasekolah di Negara maju secara historis menunjukkan rendah, sebaliknya di negara-negara berkembang menunjukkan angka yang cukup tinggi. ${ }^{9}$ Sejumlah penelitian tentang prevalensi ECC, di Thailand pada anak usia 11-14 bulan adalah 57,5\% dan pada anak usia 15-19 bulan adalah $82,8 \%{ }^{10}$ Di India prevalensi ECC pada anak usia 8-48 bulan adalah 44\%. ${ }^{11}$ Di Indonesia, khususnya di beberapa daerah seperti Bandung menunjukan bahwa prevalensi ECC pada anak usia 15-60 bulan sebesar $56,78 \% .^{12}$ Di Jakarta Utara prevalensi ECC anak usia 624 bulan adalah $63,1 \%$, dengan tingkat deft $3,3 .{ }^{13}$

Faktor-faktor yang dapat mempengaruhi perilaku orang tua terhadap pemeliharaan kesehatan gigi dan mulut ialah: a)Umur. Anak dari ibu usia muda mempunyai dmft $>0$ lebih tinggi dari anak yang ibu usia tua. Kumpulan ibu yang paling muda (kurang dari 20 tahun) 55\% daripada anak mereka mempunyai dmft $>0$ dibanding kumpulan ibu paling tua (35 tahun atau lebih) yaitu $24 \%$ dan dmft $>0 .{ }^{14}$ b)Pendidikan Formal Ibu. Lebih tinggi pendidikan formal ibu, lebih rendah frekuensi dmft anaknya. Pendidikan formal ibu yang tinggi memungkinkan prilaku terhadap pemeliharaan kesehatan gigi dan mulut berubah karena meningkatnya pemahaman mengenai informasi dan inovasi baru dalam kesehatan gigi dan mulut. ${ }^{15}$ Pekerjaan ibu juga mempunyai pengaruh, makin profesional, makin rendah dmft anaknya. 16

Dusun Wanasari merupakan dusun di kecamatan Denpasar Utara, berjarak 5,4 km dari kota Denpasar. Mayoritas penduduk bekerja pada sektor usaha kecil dan sedang, serta jasa dengan keadaan sosial ekonomi keluarga yang kurang mampu. Orang tua di Dusun Wanasari ini terbilang cukup baik dalam mengawasi atau membantu anak saat membersihkan gigi. Akan tetapi ditemukan perilaku orang tua yang kurang memperhatikan jenis makanan yang dikonsumsi anak, serta kebiasaan anak minum susu menggunakan dot. Penelitian ini bertujuan untuk menegetahui prevalensi ECC pada anak usia prasekolah di Dusun Wanasari kecamatan Denpasar Utara.

\section{BAHAN DAN METODE}

Sampel penelitian adalah 30 anak di Dusun Wanasari Kecamatan Denpasar Utara dengan usia 3-5 tahun. Jenis penelitian yang digunakan adalah deskriptif dengan pendekatan survey, menggunakan kuisioner sebagai alat pengumpulan data mengenai faktor-faktor yang berkaitan dengan ECC. Pemeriksaan intraoral dengan alat diagnosis dilakukan untuk mengetahui ECC pada anak. Data yang diperoleh selanjutnya diolah dan disajikan dalam bentuk grafik gambar. ${ }^{17}$

\section{HASIL DAN PEMBAHASAN}

A. Prevalensi Early Childhood Caries (ECC) pada Anak Usia Prasekolah di Dusun Wanasari Kecamatan Denpasar Utara

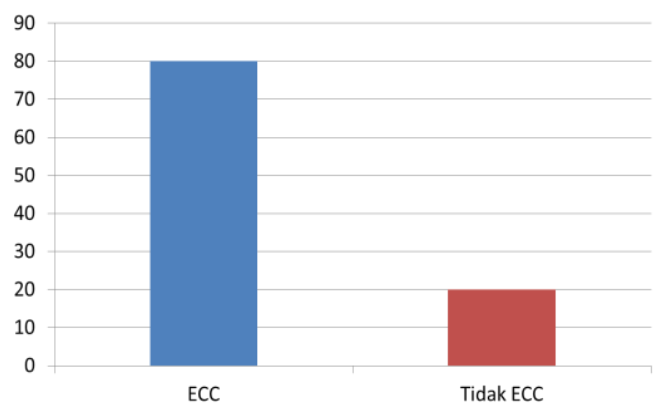

Gambar 5. Prevalensi ECC pada anak usia prasekolah di dusun Wanasari, kecamatan Denpasar Utara

B. Hasil Survey dari Pengisian Kuisioner
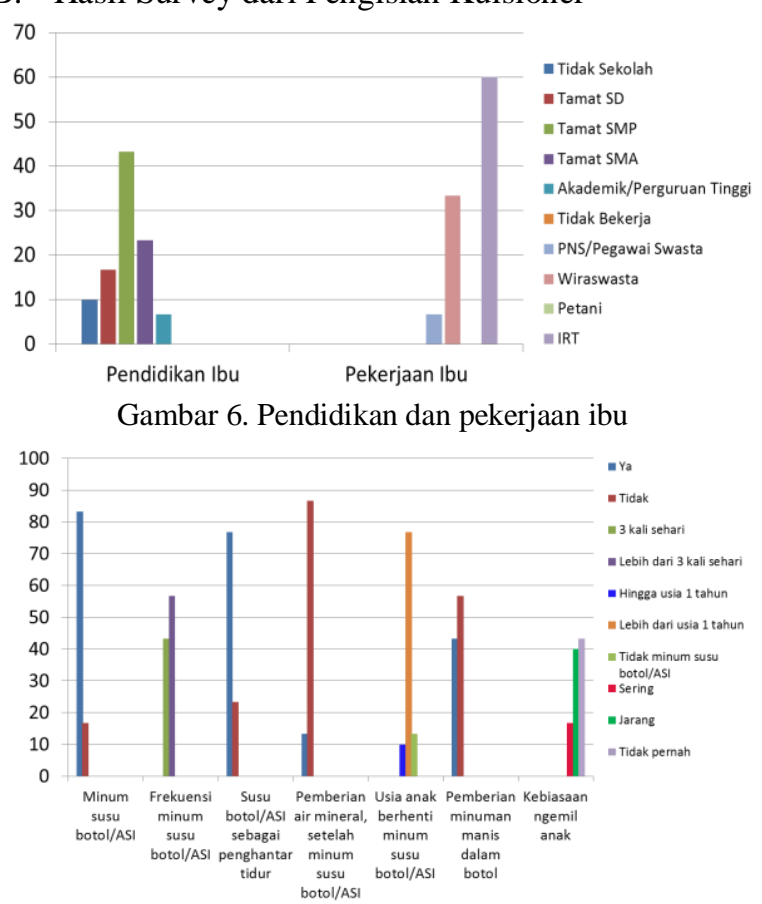

Gambar 7. Pola pemberian makan dan susu pada anak 


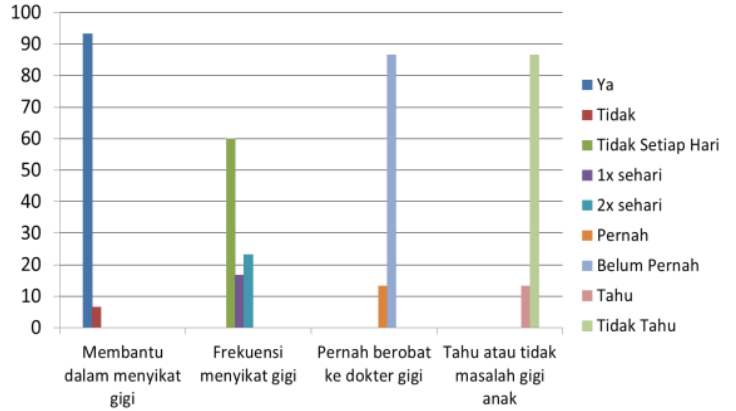

Gambar 8. Perilaku orang tua dalam memelihara kesehatan gigi dan mulut Anak.

Penelitian yang dilakukan pada anak usia 3-5 tahun di Dusun Wanasari, Desa Dauh Puri Kaja, Kecamatan Denpasar Utara menunjukkan 24 anak (80\%) yang terkena ECC dan 6 anak (20\%) yang bebas ECC. Tingginya prevalensi ECC pada daerah yang diteliti dikarenakan tingkat pendidikan orang tua yang rendah. Terlihat $10 \%$ tidak sekolah, tamat SD 16,7\%, tamat SMP menempati 43,3\%, tamat SMA $23,3 \%$ dan tamat Akademik/Perguruan Tinggi 6,7\%.

Rendahnya tingkat pendidikan orang tua akan mempengaruhi tingkat pengetahuan mereka tentang kesehatan umum dan gigi, hal ini akan mempengaruhi kesadaran dan perilaku orang tua terhadap pemeliharaan kesehatan gigi dan mulut anak. Pemahaman tentang kesehatan gigi anak rendah, akibatnya orangtua jarang membawa anak pergi ke dokter gigi, terbukti sebanyak $86,7 \%$ orang tua jarang mengajak anak untuk memeriksakan gigi secara rutin.

Pola pemberian makanan yang salah / tidak tepat pada anak merupakan penyebab terjadinya ECC. Pada penelitian ini, anak yang memiliki riwayat minum susu botol/ASI didapatkan $83,3 \%$ sedangkan yang tidak sebesar $16,7 \%$. Pemberian susu botol/ASI pada anak 3 kali sehari $43,3 \%$, sedangkan yang lebih dari 3 kali sehari sebanyak $56,7 \%$. Kebiasaan orang tua menjadikan susu botol/ASI sebagai penghantar tidur anak yaitu $76,7 \%$, sedangkan yang tidak $23,3 \%$. Orang tua juga jarang membiasakan anaknya minum air mineral setelah minum susu botol/ASI sebanyak $86,7 \%$, sedangkan yang menerapkan kebiasaan tersebut sebanyak $13,3 \%$. Usia anak berhenti mengonsumsi susu botol pada usia 1 tahun didapatkan $10 \%$, dan yang lebih dari 1 tahun $76,7 \%$.

Orang tua memberikan anaknya minum minuman manis pada botol di antara jam makan 36,7\%, sedangkan yang tidak $63,3 \%$. Kebiasaan mengemil (coklat,permen,snack) anak di antara jam makan 43,3\%, tidak setiap hari (jarang) mengemil $40 \%$, tidak pernah mengemil $16,7 \%$.

Kebiasaan mengonsumsi cairan yang mengandung karbohidrat yang mudah difermentasi (jus, susu formula, soda) dapat meningkatkan resiko karies karena kontak antara gula dalam cairan dengan bakteri pada gigi. Minuman yang mengandung gula mudah dimetabolisme oleh Streptococcus mutans menjadi asam organik yang dapat menyebabkan terjadinya demineralisasi enamel dan dentin. ${ }^{18}$ Bentuk fisik dari karbohidrat (cair, tepung, padat) yang dikonsumsi, terjadinya retensi di mulut, frekuensi makan serta lamanya interval waktu makan merupakan faktor yang dihubungkan dengan terjadinya karies. ${ }^{19}$

Hasil penelitian tentang kebersihan rongga mulut (oral hygiene / $\mathrm{OH}$ ) menunjukkan rata-rata $\mathrm{OH}$ yang buruk, terlihat prosentasi anak yang tidak menyikat gigi setiap hari cukup tinggi yaitu $60 \%$, dibandingkan yang menyikat gigi 1x sehari $16,7 \%$, sedangkan anak yang menyikat giginya $2 x$ sehari hanya $23,3 \%$. Walaupun Ibu (orangtua) yang tidak bekerja $(60 \%)$ dan yang bekerja $(6,7 \%)$ membantu anak dalam menyikat gigi, yaitu sebesar 93,3\%, sedangkan yang tidak membantu 6,7\%, tidak mempengaruhi kebersihan gigi dan mulut anaknya, hal ini disebabkan karena metode menyikat gigi yang digunakan masih belum benar. Kebersihan mulut $(\mathrm{OH})$ juga berpengaruh terhadap perkembangan ECC. Mengkonsumsi minuman yang manis secara terus menerus dengan kebersihan mulut yang buruk akan memberikan dampak yang sangat buruk bagi kesehatan gigi anak, terutama anak-anak usia dibawah 5 tahun. ${ }^{20}$

Perkembangan ECC dapat ditekan dengan melakukan pencegahan seperti menjaga kebersihan mulut sejak erupsi gigi sulung pertama. Peran serta orang tua sangat diperlukan dalam memelihara kebersihan gigi dan mulut anaknya. Tindakan pencegahan karies lainnya lebih menekankan pada pengurangan konsumsi dan pengendalian frekuensi asupan gula yang tinggi. ${ }^{19}$ Menghindari kebiasaan mengkonsumsi cairan atau makanan padat yang mengandung gula, khususnya minuman yang mengandung gula (jus, soft drink, teh manis, susu dengan tambahan gula) dengan menggunakan botol. Tidak membiarkan bayi tertidur dengan botol yang berisi susu atau cairan yang mengandung gula. Orang tua harus mengajarkan anak untuk minum dengan menggunakan cangkir pada saat anak memasuki usia 1 tahun.

Tenaga medis khususnya dokter gigi dapat melakukan konseling terhadap orang tua dalam upaya mencegah ECC, dengan menyarankan anak-anak menerima pemeriksaan gigi pertama saat berusia 6-12 bulan. $^{21}$ Pemberian informasi sebaiknya bersifat individual dan terus menerus kepada ibu dan anak, disesuaikan dengan latar belakang ibu baik tingkat ekonomi, sosial, budaya serta tingkat pendidikannya.

\section{SIMPULAN}

Pola pemberian makan (ASI atau susu) yang salah pada anak, kebersihan mulut (oral hygiene) yang buruk, sering mengkonsumsi makanan kariogenik serta status sosial ekonomi dan tingkat pendidikan orang tua yang rendah merupakan penyebab tingginya prevalensi Early Childhood Caries (ECC) pada anak usia 3-5 tahun di Dusun Wanasari.

\section{DAFTAR PUSTAKA}

1. Morris, R.E., Gillespie, G., Dashti, A., Gopalakrishnan, N.S., Al-Za'abi, F., 'Early Childhood Caries in Kuwait: Review and Policy Recommendation'. Eastern Mediterranean Health J, 1999, vol. 5, hlm. 1-2.

2. American Academy Of Pediatrics, A Pediatric Guide to Children's Oral Health, 2009, Elk Grave Village, IL:American Academy Of Pediatrics 
3. Pasareanu, M., 'Considerations regarding Early Childhood Caries'. J Preventive Medicine, 2007, vol. 15, hlm. 130-133.

4. Msefer, S., 'Early Childhood Caries: Importance of early diagnosis of Early Childhood Caries'. J Dent Quebec, 2006, hlm. 6-8.

5. Douglass, JM., Douglass, AB., Silk, HJ., 'A practical guide to infant oral health'. Am Fam Phycisian, 2004, vol. 70, hlm. 1-3.

6. Welbury, R.R., Paediatric Dentistry: Ed. 2, 2003, Oxford University Press. Oxford.

7. Kumar, V.D., 'Early childhood caries-an insight'. J Int Oral Health, 2010, vol. 2, hlm. 1-9.

8. Schroth, R.J., Smith, P.J., 'Prevalence of caries among preschool-aged Children in a Northern Manitoba Community'. J Can Dent Assoc, 2005, vol. 71, hlm. 27-33.

9. Milnes, A.R., 'Description and epidemiology of nursing caries'. J Public Health Dent, 1996, vol. 56, no. 1, hlm. 38-50.

10. Vachirarojpisan. T., Shinada. K., Kawaguchi, Y., Laungwechakan, P., Somkote, T., Detsomboonrat, P., 'Early childhood caries in children aged 6-19 months'. Community Dent Oral Epidemiol, 2004, vol. 32, hlm. 133-42.

11. Jose, B., King, N.M., 'Early childhood caries lesions in preschool children in Kerala, India'. Pediatr Dent, 2003, vol. 25, hlm. 594-600.

12. Sutadi, H. ,'Penanggulangan Karies Rampan serta keluhannya pada anak'. J. Dent Universitas Indonesia, 2002, vol. 9, no. 1, hlm. 5-8.
13. Setiawati, F., Peran pola pemberian air susu (ASI) dalam pencegahan early childhood caries di DKI Jakarta. 2010, Disertasi. Program Doktor Ilmu Kedokteran Gigi, Jakarta.

14. Clarke, J., Early Childhood Caries: Ed 1, College of Registered Dental Hygienists of Alberta. 2008

15. Wright, G., Starkey, P.E., Gardner, D.E., Child management in dentistry, 1987, hlm. 43-46.

16. Budiharto., 'Kontribusi umur, pendidikan, jumlah anak, status ekonomi keluarga, pemanfaatan fasilitas kesehatan gigi dan pendidikan kesehatan gigi terhadap perilaku Ibu'. J Dent Universitas Indonesia, 1998, vol. 6, no. 1, hlm. 12-18.

17. Aziz Alimul Hidayat,. Metodologi Penelitian Kebidanan dan Teknik Analisis Data, 2003, Salemba Medika.

18. Kawashita, Y., Kitamura, M., Saito, T., 'Early childhood caries'. International Journal of Dentistry, 2011, hlm. 1-7.

19. Angela, A., 'Pencegahan primer pada anak yang berisiko karies tinggi'. J Dent, 2005, vol. 38, no. 3, hlm. 130-134.

20. Sugito, F.S, Djoharnas, H., Darwita, R.R., 'Relationship between breastfeeding and early childhood caries (ECC) severity of children under three years old in DKI Jakarta'. Makalah Kesehatan, 2008, hlm. 87-92.

21. McDonald, R.E., Avery, D.R., Stookey, G.K. , 'Dental caries in the child and adolescent. In : McDonald, R.E., Avery, D.R., Dean, J.A. Dentistry for the child and adolescent. Ed 8. St. Louis : Mosby, 2009, hlm. 209-210. 